\title{
Impact of patient satisfaction ratings on physicians and clinical care
}

\author{
This article was published in the following Dove Press journal: \\ Patient Preference and Adherence \\ 3 April 2014 \\ Number of times this article has been viewed
}

\author{
Aleksandra Zgierska' \\ David Rabago' \\ Michael M Miller 2-4 \\ 'Department of Family Medicine, \\ University of Wisconsin-Madison, \\ School of Medicine and Public Health, \\ Madison, WI, ${ }^{2}$ American Society of \\ Addiction Medicine, Chevy Chase, \\ MD, ${ }^{3}$ Department of Psychiatry, \\ University of Wisconsin-Madison, \\ School of Medicine and Public Health, \\ ${ }^{4}$ Herrington Recovery Center, Rogers \\ Memorial Hospital, Oconomowoc, \\ WI, USA
}

Background: Although patient satisfaction ratings often drive positive changes, they may have unintended consequences.

Objective: The study reported here aimed to evaluate the clinician-perceived effects of patient satisfaction ratings on job satisfaction and clinical care.

Methods: A 26-item survey, developed by a state medical society in 2012 to assess the effects of patient satisfaction surveys, was administered online to physician members of a state-level medical society. Respondents remained anonymous.

Results: One hundred fifty five physicians provided responses (3.9\% of the estimated 4,000 physician members of the state-level medical society, or approximately $16 \%$ of the state's emergency department [ED] physicians). The respondents were predominantly male (85\%) and practicing in solo or private practice (45\%), hospital (43\%), or academia (15\%). The majority were ED (57\%), followed by primary care (16\%) physicians. Fifty-nine percent reported that their compensation was linked to patient satisfaction ratings. Seventy-eight percent reported that patient satisfaction surveys moderately or severely affected their job satisfaction; $28 \%$ had considered quitting their job or leaving the medical profession. Twenty percent reported their employment being threatened because of patient satisfaction data. Almost half believed that pressure to obtain better scores promoted inappropriate care, including unnecessary antibiotic and opioid prescriptions, tests, procedures, and hospital admissions. Among 52 qualitative responses, only three were positive.

Conclusion: These pilot-level data suggest that patient satisfaction survey utilization may promote, under certain circumstances, job dissatisfaction, attrition, and inappropriate clinical care among some physicians. This is concerning, especially in the context of the progressive incorporation of patient satisfaction ratings as a quality-of-care metric, and highlights the need for a rigorous evaluation of the optimal methods for survey implementation and utilization.

Keywords: physician satisfaction, quality of care, patient experience of care, health services

\section{Introduction}

Patient experience of care, or "satisfaction", is a crucial element of patient-centered care, the implementation of which has become the focus of wide-scale efforts aimed at improving health and health-care delivery. ${ }^{1-3}$ Results from patient satisfaction surveys can facilitate positive change and quality improvement (QI) initiatives in health-care delivery that are responsive to patients' needs. Data support the potential benefits of high patient satisfaction; satisfied patients can have increased treatment adherence and may improve health outcomes. ${ }^{4,5}$ 
However, several studies have also raised concerns suggesting the use of patient satisfaction ratings as a quality-ofcare marker may be associated with unexpected, undesirable outcomes. ${ }^{6,7}$ A prospective cohort study of a representative sample of US adults $(\mathrm{N}=51,946)$ found that, when compared with those least satisfied, the most satisfied patients had $12 \%$ higher odds of hospital admission, 9\% greater expenditures for both health services and prescription drugs, and a $26 \%$ higher mortality risk, which increased to $44 \%$ when additionally adjusted for baseline health status and comorbidities. ${ }^{6}$ Because patients' treatment satisfaction may rely more on their perception of met expectations than on objective medical outcomes, ${ }^{7-12}$ one possible explanation for such findings can be that the pursuit of and incentivizing high survey scores may encourage inappropriate medical practices. ${ }^{13,14}$

Incentivizing clinicians to meet patient satisfaction score "benchmarks" has become common and stirred heated debates in the professional and lay press. ${ }^{13-25}$ However, formal evaluation of the effects of patient satisfaction ratings on clinicians and clinical practice patterns is lacking. The goal of this project, therefore, was to assess physicians' perceptions about the impact of patient experience of care surveys on their job satisfaction and clinical practice.

\section{Methods}

\section{Design}

This was a cross-sectional electronic survey study, conducted by a state-level medical society. Survey responses were received by the authors as de-identified aggregate data. Because the manuscript preparation did not involve human subjects as defined by federal regulations and the authors were not involved in the design or conduct of this project, the study was determined to be exempt from review by an institutional review board.

\section{Setting and population}

Active physician members of a state medical society, regardless of specialty or practice setting, were invited to complete the survey.

\section{Protocol}

In 2011, officials in the medical society of a US state noted receiving substantial spontaneous feedback from its members voicing concerns that incorporation of patient experience of care ratings into the "benchmarking" processes (ie, tying them to clinician compensation, bonuses, contract lengths, and even continuation of employment) promoted physician job dissatisfaction and inappropriate clinical practices (personal communication). After a review of existing anecdotal and limited research evidence, the society's staff and invited consultants developed a 26-question QI survey. Between March and July 2012, the state medical society sent an invitation and six follow-up reminders via email to its approximately 4,000 active physician members to participate in the anonymous online survey hosted by Survey Monkey ${ }^{\circledR}$. The invitation was also distributed through announcement in a weekly electronic newsletter and a posting on the society's website and social media sites (Facebook ${ }^{\circledR}$, Twitter $^{\circledR}$ ).

\section{Outcome measures}

The 26-item survey inquired about respondents' demographics and their perceptions about the influence of patient experience of care surveys on job satisfaction and clinical care. Items 1-25 called for demographic information and quantitative responses ("Yes/No/I don't know" or ordinal response scale answers). Item 26 asked respondents to address the statement: "Please provide us with any additional details that you would like to share."

\section{Data analysis}

The authors adapted a standard method to analyze the first-person qualitative data ${ }^{26}$ provided in item 26 of the survey. Each respondent's qualitative comments were reviewed individually by each of the first two authors using a standardized worksheet. They were then discussed by the authors in three meetings over 6 weeks using a consensus approach to identify and code major themes. Disagreements were resolved by consensus. SurveyMonkey ${ }^{\circledR}$ (SurveyMonkey, Palo Alto, CA, USA) was used for data compilation and descriptive statistics. Due to the small sample size and low response rate, no comparisons between subgroups were conducted.

\section{Results}

The survey was completed by 155 respondents (response rate $3.9 \%$ among the estimated 4,000 active physician members of the society, and $16 \%$ among the estimated 551 active emergency medicine physicians in the state in 2012). All respondents completed the demographic portion of the survey; 131 physicians responded to items about the influence of patient satisfaction surveys. Qualitative responses were provided by 52 physicians.

The majority of the 155 respondents were men (84.5\%) who were locally practicing physicians $(96.1 \%)$. Almost all (96.1\%) reported that their hospital or employer utilized patient experience of care surveys. Almost half (43.2\%) 
were hospital employed, $34.8 \%$ worked in a private group practice, $9.7 \%$ in a solo practice, and $14.8 \%$ in an academic medical center practice setting (Table 1). The respondents represented multiple specialties. The largest set of respondents comprised emergency department (ED) physicians ( $56.8 \%$ of respondents or $16 \%$ of the state's ED physicians), followed by primary care (16.1\%: family medicine, internal medicine, and pediatrics), and obstetrics/gynecology (3.9\%). Eleven percent indicated "other medical specialty" and 11\% indicated "other surgical specialty" (Table 1).

Fifty-two physicians provided qualitative comments. Analysis identified several themes in these responses, as summarized in Table 2. Six physicians provided neutral $(\mathrm{N}=3)$ or positive $(\mathrm{N}=3)$ feedback regarding the use of patient satisfaction surveys. The three positive statements noted that written patient comments could be useful but that numerical scores of patient experience of care were not helpful for practice improvement initiatives. The remaining 46 responses presented a negative view of the survey impact on clinicians and their practices, with responses falling into one of five main themes. Theme 1 $(\mathrm{N}=28)$ was that patient satisfaction surveys were viewed as a poor surrogate measure of the quality of medical care. Regarding patient satisfaction survey methodology, physicians $(\mathrm{N}=18)$ expressed concerns about the validity and reliability of satisfaction surveys due to skewed sampling methods that excluded or potentially over-sampled certain clinical populations (eg, patients admitted from the ED to the hospital did not complete surveys about their ED care; multiple surveys could be completed by those who frequent EDs, with some patients potentially using the surveys as a tool to achieve their goals such as "drug seeking") or

Table I Sample characteristics by sex, practice setting, and specialty

\begin{tabular}{ll}
\hline Characteristic & $\begin{array}{l}\text { Survey respondents } \\
(\mathbf{N}=155)\end{array}$ \\
\hline Male sex, $\mathrm{n}(\%)$ & $131(84.5)$ \\
Practice setting, $\mathrm{n}(\%)$ & \\
Hospital employed & $67(43.2)$ \\
Private group practice & $54(34.8)$ \\
Academic medical practice & $23(14.8)$ \\
Solo practitioner & $15(9.7)$ \\
Specialty, $\mathrm{n}(\%)$ & \\
Emergency & $88(56.8)$ \\
Family medicine/internal medicine/pediatrics & $25(16.1)$ \\
Obstetrics/gynecology & $6(3.9)$ \\
Orthopedics & $3(1.9)$ \\
Hospitalist & $\mathrm{I}(0.6)$ \\
Other medical specialty & $17(\mathrm{II.0)}$ \\
Other surgical specialty & $17(\mathrm{II} .0)$ \\
\hline
\end{tabular}

the respondent sample size often being too small to draw statistically meaningful conclusions regarding a particular physician's care. In addition, physicians believed it was not appropriate for patients to rate the physician's medical judgment or management $(\mathrm{N}=6)$ and that surveys made them feel like "minor service providers" rather than highly trained professionals $(\mathrm{N}=5)$. Theme 2 was the physicians' perception that patient satisfaction surveys promoted inappropriate medical practices $(\mathrm{N}=16)$, including inappropriate prescribing of opioids $(\mathrm{N}=10)$ and antibiotics $(\mathrm{N}=4)$. Theme 3 was that too much weight was placed on patient satisfaction survey results while not enough administrative effort was dedicated toward improving medical care and outcomes $(\mathrm{N}=13)$. Although physicians acknowledged that evaluating patient satisfaction is important, they felt "the pendulum had swung too far" $(\mathrm{N}=9)$, and expressed frustration about unsatisfactory responses from administrators to physicians' survey-related concerns $(\mathrm{N}=8)$. Theme 4 described physicians' dilemmas and frustration with a perceived "conflict of interest" $(\mathrm{N}=12)$ between the need to generate high satisfaction scores and the need to provide high-quality medical care, especially when clinician salaries were tied to the survey scores, thus potentially promoting inappropriate practices to "boost" satisfaction scores $(\mathrm{N}=6)$, or when appropriate medical care may result in an unhappy patient $(\mathrm{N}=6)$. Finally, ten respondents viewed patient satisfaction surveys as a "punitive tool" used against physicians (Theme 5), with four respondents expressing fear of losing their job in relation to patient satisfaction survey results.

Table 3 summarizes responses $(\mathrm{N}=131)$ regarding the implementation and use of patient satisfaction surveys. When asked how many times in the past 6 months they were provided the results of patient satisfaction surveys, many physicians reported not knowing about such results (45\%) or reported receiving summary data pooled from 20 or fewer surveys (29.8\%). Most of the respondents (61.8\%) did not know the patient satisfaction survey response rate for their hospital or practice. The majority reported not knowing their average "raw score" or percentage rank (62.6\% and 53.4\%, respectively). Over one-third of clinicians reported not knowing their hospital or practice targets for "excellent" scores or percentile rank for patient satisfaction ratings; almost half of the respondents (44.2\%) stated their belief the target was set at $90 \%$ or above. Over half $(58.8 \%)$ reported that part of their compensation was tied to patient satisfaction survey results. Approximately half of respondents also stated they were able to get copies of completed patient satisfaction 
Table 2 Selected qualitative physician $(\mathrm{N}=52)$ responses* to the question: "Please provide us with any additional details you would like to share"

\section{Neutral or positive comments, $\mathbf{N}=6$}

- "Patient comments and surveys are useful to gauge my performance. If I read a comment that suggests a problem with my office or hospital practice, it makes me look into the processes."

- "I find the comments the families write in to be useful. The numerical scores are not so helpful."

- "Still one of the few independent practices."

- "Sometimes they provide useful information and we have made improvements based on that information."

- "None" [no comments].

- "Many times the hospitals don't like them either, but the Feds are pushing it."

Negative comments, $\mathrm{N}=47$

Theme I: poor way to evaluate quality of medical care, $\mathrm{N}=\mathbf{2 8}$

Methodological issues, $\mathrm{N}=18$

- "Extremely poor way to measure the quality of medical service."

- "Our surveys are based on a very small percentage of overall patients and the statistics generated are therefore meaningless ... In fact, the subset of patients that qualify for the survey in our 'emergency department' are the non-ill patients with mild upper respiratory infections, narcotic-seeking behaviors, nonobstetric vaginal bleeding, acute/chronic alcohol intoxication and anti-social behaviors, not the ill ones who require a significantly higher level of service. It's extremely frustrating."

- "In the emergency department it is not uncommon for patients who are seen frequently (ie, frequent flyers) - sometimes as often as 3 or 4 times/ week - to receive multiple surveys. For an administration to base any decisions on such patients is ludicrous."

- "Statistically their wide swinging month to month values show that they are invalid!!"

- "I feel statistically that satisfaction scores are flawed. One patient does not like you and gives you zeros and your whole quarter is shot."

- "These are more often completed by unhappy patients, rather than a broad cross section."

- “... the surveys are used by patients as complaint forms ... hardly anyone bothers to fill out a survey if they felt their experience was 'as expected'. If you don't believe me, then I challenge you to take the time to call the phone number on the back of the next semitractor trailer you see on the highway who is doing his job as expected, ie: going the speed limit and not being reckless ... 'how's my driving?' You don't care or have the time to call that number if the guy is doing his job as expected ... now let's assume he didn't meet your expectations, would you be more inclined to call?' [ellipses in original].

- "I think it is a good idea to ask the patients how they feel about the care that they have received, but too many patients have found how to get what they want by complaining."

- "The pool of respondents is low and skewed by drug seekers and unrealistic expectations by patients."

- "... not a true reflection of the quality of the care rendered."

- "There is a disconnect between my ... scores, and what I am told by the nurses and staff that work with me on a daily basis ... Likewise, if my patients really thought I was in the bottom quartile, why are they still seeing me when there are plenty of physicians in the area still accepting patients?"

Patients should not rate appropriateness of medical decisions, $\mathrm{N}=6$

- "Patient satisfaction should not be linked to physician judgment and should not be utilized to 'grade' a doctor's performance."

- "Generally, patients are only qualified/educated enough to comment on things such as wait times, cleanliness, and physician friendliness/demeanor, etc."

- "Patients should respond about physician office administration - timeliness, staff interactions, etc. Patients should not be asked to respond to questions that might imply care was appropriate or not."

- "The physician's decisions should be based upon training and appropriate current treatment trends - not upon whether the patient 'agrees or is satisfied' with the treatment."

- "[I would] rather get fired than practice bad medicine. They are not physicians and should not tell us what to do in regard to treating patients." Physicians felt misclassified as minor service providers rather than highly trained professionals, $\mathrm{N}=5$

- 'In my opinion, satisfaction surveys tend to rate 'hotel' aspects of care. While efficiency and other business concerns offer room for improvement, the essential issue to me is should that be the primary measure (rather than actual quality of care) that drives the 'business' of medicine. If 'the customer is always right,' why devote the years of training?"

- "Medicine is not customer service, we make decisions based on appropriate medicine, not to make people happy."

- "... the practices that require high satisfaction scores are calling patients and encouraging them to mark high scores. My last used car salesman did the same thing."

- "These are generally worthless devices. While they may be great for determining 'Customer Satisfaction' at a Hardware store or a Car Dealership they are absolutely inappropriate in the medical setting."

- "Medicine should not be treated like the restaurant or hospitality industry. We are not supposed to make everyone 'happy.' This phenomenon is contributing to the skyrocketing costs of medicine, narcotic addiction, and antibiotic resistance."

Theme 2: patient satisfaction surveys can promote inappropriate medical practices, $\mathbf{N}=16$

- "Narcotic seekers are another huge problem and they are well aware of the patient satisfaction scores and how they can use these threats and complaints to obtain narcotics."

- "I give a few pain pills to seekers who I would previously have said no. I have given the occasional antibiotic to the frantic mother who demands an unnecessary abx [antibiotic]."

- "... we practice bad medicine as a result of [the patient satisfaction] surveys."

- "Narcotic abuse is the biggest problem because the drug seeker knows the game and threatens to call administration more than any other group." 
Table 2 (Continued)

Theme 3: too much weight on patient satisfaction survey results, not enough administrative effort to improve medical outcomes, $\mathrm{N}=\mathrm{I} 3$ Too much weight is given to patient satisfaction, $\mathrm{N}=9$

- “... hospital administration places significant emphasis on these statistics rather than actual patient medical care, including tying my financial reimbursement to them."

- "I don't think the surveys are a reliable source of information nor do I think they should cause any significant changes in the clinical setting ... My impression is that there is entirely too much effort and emphasis placed on surveys that I largely ignore ... That puts entirely too much weight on I portion of the ' 360 ' evaluation ... There should be an avenue in place for this, but it just seems to be carrying excessive weight in the last 5 yrs."

- "I do feel way too much emphasis is paid to patient surveys."

- "Administrators are more concerned with these scores than whether or not we are prescribing unnecessary antibiotics and narcotics. More concerned with patient satisfaction than quality medical care."

- "... hospitals are overly focused on these scores. Administration should focus more on patient outcomes though this is much more difficult to quantify."

- "The pendulum has swung too far."

- "Patient satisfaction has a place but is currently being over utilized ... Physicians should try to communicate effectively with patients but striving for excellent survey results should not be a primary goal. Good medicine should be the goal."

Unsatisfactory response from administrators, $\mathrm{N}=8$, including poor efforts to improve medical outcomes $(\mathrm{N}=7)$ or effectively communicate with clinicians ( $\mathrm{N}=3$ )

- "This is a significant job dissatisfier, but adm [administration] is not willing to negotiate a change."

- "There is constant conflict between increasing the number of patients seen, completing electronic medical records - which add significant time to the encounter, and making sure the patient is 'pleased and happy' with the care they have received. There is almost NO EFFORT directed to improving the care provided."

- "The hospital only cares about how it is perceived versus true quality."

- "Administrators are more concerned with these scores than whether or not we are prescribing unnecessary antibiotics and narcotics. More concerned with patient satisfaction than quality of medical care."

- "Administration should focus more on patient outcomes though this is much more difficult to quantify."

- "Although we all agree that it is important to have 'satisfied patients' administrators are more concerned with these scores than whether or not we are prescribing appropriate antibiotics or if we are contributing to the epidemic of prescription drug abuse."

Theme 4: perceived as a "conflict of interest", $\mathrm{N}=12$

... when tying physician's salary to patient satisfaction, $\mathrm{N}=6$

- "Doctors compensation at our hospital is tied to satisfaction scores, which is clearly a conflict of interest."

- "Correlating [patient satisfaction survey results] to pay or terms of employment is ludicrous."

- "Patient satisfaction surveys push physicians to unethical behaviors, especially when they are tied to physician compensation."

... when making appropriate medical decisions can make patients unhappy, $\mathrm{N}=6$

- "Unfortunately many of the problems we see in the ED [emergency department] are related to poor lifestyle choices and non-compliance. People are not happy to hear the truth about this on most instances and those that are unhappy are the most likely to respond."

- "Patients often want prescriptions, tests and procedures that are not in their best interest."

- "... appropriate medical care often entails diagnostics and therapeutics which are inherently uncomfortable and are likely to lead to "patient dissatisfaction', subsequently reflected in negative responses to unrelated questions on these surveys. If one could, would one opt for the pleasant experience in the care focused on pleasing the patient, or the unpleasant experience shown to improve quality of life ultimately? Note that, despite the push for patient autonomy, we often gravely overestimate the ability of the patient to determine the best course. I see this all the time, having to lead them out of inappropriate choices."

- "Telling a patient with a viral infection that they do not need an antibiotic is good medicine but may lead to poorer satisfaction scores."

- "If you are pleasing all of the people you are doing something wrong. Many are unreasonable and have an agenda requesting inappropriate things."

Theme 5: perceived as punitive tool contributing to job dissatisfaction, $N=10$, including fear of losing a job (N=4)

- "I find it crazy that I could lose my job (I know of one of my partners who had to meet with administration and was to be fired except that month's survey came in and his was fine)."

- "An unfortunate use of a tool that might be able to be helpful to find glaring errors in a practice setting but rather than helpful, punitive."

- "... 3 physicians were given substantially shorter contract durations than the remainder of the group predicated solely on [patient satisfaction] scores."

- "Instead of using surveys as tool for improvement employers are using results as a weapon against providers."

- "Even though our group has not been directly threatened by administration to keep satisfaction scores up we still feel that poor scores could endanger our continued contract with the hospital."

Note: *Misspelled words have been corrected to improve readability.

surveys $(48.9 \%)$ and had approached their employer in the past to discuss these surveys (56.5\%).

When asked about experiences and perceptions related to patient satisfaction surveys (Table 4; $\mathrm{N}=131$ ), approximately one-third of the responding physicians reported considering quitting their current job (28.2\%) or leaving the profession of medicine $(28.2 \%)$ because of patient satisfaction survey use in their workplace. Twenty-six physicians (19.8\%) reported their employment had been threatened as a direct result of patient satisfaction surveys. The majority (77.9\%) felt that 
Table 3 Clinician $(\mathrm{N}=|3|)$ responses to questions related to patient satisfaction survey implementation

\begin{tabular}{|c|c|}
\hline Question & $\begin{array}{l}\text { Response } \\
\text { count (\%) }\end{array}$ \\
\hline \multicolumn{2}{|c|}{ Number of surveys received in the past 6 months } \\
\hline $0-10$ & $27(20.6)$ \\
\hline $11-20$ & $12(9.2)$ \\
\hline $21-40$ & $13(9.9)$ \\
\hline $4 I-60$ & II (8.4) \\
\hline $61+$ & $9(6.9)$ \\
\hline I don't know & $59(45.0)$ \\
\hline \multicolumn{2}{|c|}{ "Raw score" average over the past 3 months } \\
\hline $91-100$ & $16(12.2)$ \\
\hline $81-90$ & $22(16.8)$ \\
\hline $61-80$ & $9(6.8)$ \\
\hline 60 or less & $2(1.5)$ \\
\hline I don't know & $82(62.6)$ \\
\hline \multicolumn{2}{|c|}{ Percentage rank average over the past 6 months } \\
\hline $8 I-100$ & $37(28.2)$ \\
\hline $61-80$ & $10(7.6)$ \\
\hline 60 or less & $14(10.7)$ \\
\hline I don't know & $70(53.4)$ \\
\hline \multicolumn{2}{|c|}{ Hospital or practice's goal for "excellent" scores or percentile rank } \\
\hline $91 \%-100 \%$ & $58(44.2)$ \\
\hline $81 \%-90 \%$ & $15(11.4)$ \\
\hline $80 \%$ or less & $6(4.7)$ \\
\hline I don't know & $52(39.7)$ \\
\hline \multicolumn{2}{|c|}{ Approximate response rate for hospital or practice's surveys } \\
\hline At least $30 \%$ & $4(3.1)$ \\
\hline $21 \%-30 \%$ & $3(2.3)$ \\
\hline $11 \%-20 \%$ & $10(7.6)$ \\
\hline $2 \%-10 \%$ & $19(14.5)$ \\
\hline Less than $2 \%$ & $14(10.7)$ \\
\hline I don't know & $81(61.8)$ \\
\hline \multicolumn{2}{|c|}{ Are the results of your surveys tied to financial compensation? } \\
\hline Yes & $77(58.8)$ \\
\hline No & $48(36.6)$ \\
\hline I don't know & $6(4.6)$ \\
\hline \multicolumn{2}{|c|}{ Are you able to get copies of completed surveys? } \\
\hline Yes & $64(48.9)$ \\
\hline No & $31(23.7)$ \\
\hline I don't know & $36(27.5)$ \\
\hline \multicolumn{2}{|c|}{$\begin{array}{l}\text { Have you ever approached your employer to discuss patient satisfaction } \\
\text { surveys? }\end{array}$} \\
\hline Yes & $74(56.5)$ \\
\hline No & $57(43.5)$ \\
\hline
\end{tabular}

patient satisfaction surveys "moderately" or "severely" affected their job satisfaction. About half of clinicians reported ordering an inappropriate test and prescribing inappropriate antibiotic or opioid pain medication as a result of patient satisfaction scores. Some (17.6\%) endorsed performing a procedure they believed to be unnecessary and one-third (33.6\%) reported they had unnecessarily admitted a patient into the hospital because of patient satisfaction surveys. Almost half (48.1\%) felt they had practiced inappropriate patient care as an outcome of patient satisfaction ratings.
Table 4 Clinician $(N=|3|)$ experiences and perceptions related to patient satisfaction surveys

\begin{tabular}{|c|c|}
\hline Question & $\begin{array}{l}\text { Response } \\
\text { count (\%) }\end{array}$ \\
\hline \multicolumn{2}{|c|}{$\begin{array}{l}\text { Have you ever considered quitting your current job because of patient } \\
\text { satisfaction surveys? }\end{array}$} \\
\hline Yes* & $37(28.2)$ \\
\hline \multicolumn{2}{|c|}{$\begin{array}{l}\text { Have you ever considered leaving the profession of medicine because o } \\
\text { patient satisfaction surveys? }\end{array}$} \\
\hline Yes* & $37(28.2)$ \\
\hline \multicolumn{2}{|c|}{$\begin{array}{l}\text { Has your employment ever been directly threatened as a result of these } \\
\text { surveys? }\end{array}$} \\
\hline Yes* & $26(19.8)$ \\
\hline \multicolumn{2}{|c|}{ Have these surveys affected your job satisfaction? } \\
\hline Severely & $3 \mid$ (23.7) \\
\hline Moderately & $71(54.2)$ \\
\hline Not at all & $29(22.1)$ \\
\hline
\end{tabular}

Have you ever ordered a test that you felt to be inappropriate in direct response to patient satisfaction surveys?

Yes* 72 (55.0)

Have you ever prescribed what you felt to be an inappropriate antibiotic in direct response to patient satisfaction surveys?

Yes*

$67(5 I .1)$

Have you ever prescribed what you felt to be an inappropriate narcotic pain medication in direct response to patient satisfaction surveys?

Yes*

$63(48.1)$

Have you ever performed a procedure you felt to not be needed because of patient satisfaction scores?

Yes* 23 (17.6)

Have you ever operated on a patient when you felt it was not necessary because of patient satisfaction scores?

$\begin{array}{ll}\text { Yes } & 0(0) \\ \text { No } & 56(42.7) \\ \text { N/A } & 75(57.3)\end{array}$

Have you ever admitted a patient into the hospital because of patient satisfaction scores?
Yes*
$44(33.6)$

How often do you feel you practice inappropriate patient care based on patient satisfaction scores?

$\begin{array}{ll}\text { Often } & 18(13.7) \\ \text { Sometimes } & 45(34.4) \\ \text { Rarely } & 36(27.5) \\ \text { Never } & 32(24.4)\end{array}$

Please respond to the following statement, "My employer agrees with the results from patient satisfaction surveys and they are here to stay, regardless of physician concerns."

Yes*

III (84.7)

Note: *The question had "yes" or "no" response options.

The vast majority $(84.7 \%)$ endorsed the statement that their employers support conducting patient satisfaction surveys regardless of concerns raised by physicians.

\section{Discussion}

Results from a survey of physicians in a single state in the USA suggest that patient experience of care ("satisfaction") surveys, as implemented and utilized in the institutions in 
which they practiced, can lead to physician job dissatisfaction, attrition (exit from the workforce), and inappropriate clinical care, especially if data from patient experience of care surveys are perceived by physicians as a punitive tool regarding compensation or other negative professional consequences. Surveyed physicians also voiced lack of trust in the validity and reliability of survey results, and frustration that administrators did not seem to value their concerns regarding patient satisfaction surveys.

Striving for high patient satisfaction is important, valuable, and a crucial element of patient-centered care. QI initiatives that are responsive to patients' needs can improve patient satisfaction; in turn, satisfied patients may have better treatment adherence and outcomes. ${ }^{4,5}$ Interestingly, some studies report that treatment satisfaction may rely more on the patient's perception of met expectations rather than objective medical outcomes, ${ }^{7-11}$ and recent publications suggest that utilizing patient satisfaction ratings as a quality-of-care marker may even be harmful. ${ }^{6,13,14}$ Findings from this pilot study add the perspective of a subset of physicians to this issue and call for the careful evaluation of the effects, especially regarding implementation and utilization, of patient experience of care surveys on clinicians, and clinical care patterns and outcomes.

The most worrisome issue raised by our data is that the use of patient satisfaction surveys may promote, at least among some clinicians and under certain circumstances, a culture of care that can be partially driven by satisfaction score rather than evidence based; this can potentially compromise health-care outcomes as well as violate clinicians' sense of professional integrity, ${ }^{27}$ contributing, in turn, to job dissatisfaction. Most of the responding physicians were dissatisfied, with some reporting they were considering leaving medical practice as a result of patient satisfaction surveys. The majority of responding physicians were also concerned that such surveys promoted inappropriate medical practices, including unnecessary antibiotic and opioid pain medication prescriptions, tests, procedures, and hospital admissions. Physicians' experience of professional roles and their own satisfaction with clinical practice are crucial elements for the stability of physician workforce, an issue which is a component of one of the top three strategic priorities in the American Medical Association's (AMA) recently revised strategic plan. ${ }^{28}$ With America facing physician workforce shortages, especially in primary care, ${ }^{29}$ as well as increasing costs of health care, ${ }^{30}$ growing antibiotic resistance, ${ }^{31}$ and an epidemic of prescription drug abuse, ${ }^{32}$ optimizing system-wide efforts to encourage both evidence-based practice patterns and physician job satisfaction and retention are particularly timely.

These findings are especially important in the context of widespread and broadening utilization of patient satisfaction ratings as an integral element of quality-of-care metrics. Most health-care-related quality metrics assess care processes and health outcomes. With increased emphasis on patientcentered care, patient satisfaction is playing a progressively more prominent role as a surrogate measure of health-care quality. Private sector hospitals, clinics, and health insurance plans collect patient experience of care data for their own use, and many develop initiatives aimed at improving patient satisfaction scores. Reported strategies include incentivizing clinicians by tying physician compensation, academic faculty promotion, or even job retention to patient satisfaction score "benchmarks". Recently, significant effort and resources have been allocated to patient satisfaction data collection and reporting by the Medicare program ${ }^{33,34}$ of the federal Centers for Medicare and Medicaid Services (CMS). The CMS's Hospital Compare and Physician Compare websites publicly report and compare data for hospitals and individual physicians, including cost data, outcome data, and patient experience of care data. Payments to hospitals are now linked to hospital performance not only in generating optimal clinical outcomes and minimizing medical errors but also in creating satisfying experiences for patients, as measured by the CMS's Hospital Consumer Assessment of Healthcare Providers and Systems (HCAHPS) initiative. As a result, hospitals encourage their physicians to make decisions facilitating improvement in the hospital's HCAHPS scores. Our preliminary findings are consistent with the existing limited evidence suggesting that certain methods of implementation and/or utilization of patient satisfaction surveys may have unintended negative consequences. If corroborated, this may have substantial policy- and practice-level implications.

Interestingly, the majority of survey respondents were male physicians, specializing in emergency medicine. Our data do not explain whether or why these physicians may be more dissatisfied or more likely to respond to a survey on patient satisfaction ratings than their counterparts. The higher response rate among ED physicians (16\% of the state's ED physicians in 2012) may, for example, indicate that these physicians are under more scrutiny with respect to patient experience of care measures or may face "tighter" linkages between patient satisfaction scores and professional incentives (financial and emotional rewards from practice). They may also disproportionately find themselves in challenging clinical situations involving patient expectations 
which - in the physician's professional judgment - are not aligned with the patient's best interests. It is also possible that patients may rate ED physicians more "harshly" than they would have rated, under similar circumstances, their continuity clinicians, because the doctor-patient relationship is not as well-established in the acute-care setting. In turn, worse satisfaction ratings may negatively affect the ED clinicians who then voice their dissatisfaction. A study of 7,245 adult Swedish patients from a variety of medical specialty settings found that younger ED patients comprised the least satisfied patient group, and that met expectations were among the top predictors of patient satisfaction. ${ }^{11}$ Physicians in our study voiced their belief that the use of patient satisfaction ratings had negative effects on their clinical care, especially on opioid prescribing. Issues surrounding opioid prescribing may contribute disproportionately to ED physicians' dissatisfaction given the clinical challenge of pain-related diagnoses and an epidemic of prescription drug abuse. Provision of adequate analgesia, pain-related communication, and the administration of oral opioids were the main contributors of satisfaction ratings among ED patients with pain. ${ }^{35}$ The possible negative influence of patient satisfaction-based benchmarks on pain management and opioid prescribing practices has recently been raised by the AMA, whose 2013 report calls for the CMS to suspend the use of HCAHPS-based patient satisfaction ratings on pain management until their validity as a reliable and accurate measure of quality of care is determined. ${ }^{36}$

\section{Limitations}

The survey, developed as a part of a QI project, has a methodological limitation. Its design does not allow us to isolate the effect of patient satisfaction surveys from the potential effect of other factors that may influence physicians' perceptions and decision making, including, for example, malpractice concerns.

Additionally, the low overall response rate and the relative dominance of ED and male physicians among the respondent pool substantially limit the generalizability of these findings, raising the potential for response bias. However, the consistency of the negative perceptions of patient satisfaction survey impact is compelling and suggests a coherent viewpoint among the responding physicians that is aligned with concerns described in the AMA's recent report. ${ }^{36}$ In addition, when estimating the response rate by specialty, ED physician respondents comprised $16 \%$ of all practicing ED physicians in the surveyed state in 2012, regardless of their medical society membership. The fact that close to $30 \%$ of the surveyed physicians considered not only quitting their current job but also the practice of medicine is worrisome, even in light of the limitations of this study.

Although our data suggest that patient satisfaction surveys may promote inappropriate medical practices among some clinicians, the data may reflect a very different kind of association: it is also possible that our respondents were drawn from a subgroup of clinicians who had provided suboptimal care. If this were the case, it could be that physicians' practices led to worse patient experience of care ratings which, in turn, resulted in negative consequences for these physicians and, subsequently, increased their likelihood of responding to and airing grievances through an anonymous survey. Thus, responses of the surveyed physicians may represent the voice of a small number of subpar practitioners who were identified via patient experience of care evaluation processes.

Finally, the fact that a large proportion of the surveyed physicians did not know their raw score or percentage rank, both of which make up the "summary scores" of patient satisfaction surveys, may mean that they did not receive feedback on their individual scores; therefore, their perceptions may reflect a general hesitance toward using patient satisfaction data rather than a specific personal experience.

\section{Future directions}

These pilot data suggest that current methods of assessment and use of patient satisfaction ratings may, under certain circumstances, have unintended negative consequences for health-care delivery processes and treatment outcomes. They suggest the need for the further investigation of optimal methods to implement and utilize patient experience of care measures to foster patient centeredness, evidencebased clinical practice, and physician job satisfaction. ${ }^{37-39}$ Examples of such strategies include the provision of regular constructive feedback to individual clinicians; targeted training in communication skills; and venues for open, positive communication between physicians and administration. Identifying subpopulations of patients for whom a different approach to the utilization of patient satisfaction ratings may be warranted (eg, persons with addiction or others seeking opioid prescriptions), could also promote positive change in physicians' perceptions of the use of patient satisfaction measures. 


\section{Conclusion}

These state-level data suggest that the system-wide utilization of patient satisfaction surveys may lead to job dissatisfaction and medically inappropriate clinical care among some physicians. These preliminary findings are concerning, especially in the context of the widespread and progressive utilization of patient satisfaction ratings as an integral metric of quality-of-care assessment, and call for a more rigorous evaluation of the use of patient satisfaction surveys and the linkage of data from such surveys to other variables (such as physician compensation, job retention, or job promotion). At the very least, these results are so intriguing that they call for additional investigations of the associations between patient experience of care evaluation activities and physician practice satisfaction.

\section{Acknowledgments}

Our thanks to the staff of the state medical society for their assistance with this data.

\section{Disclosure}

A Zgierska is supported by grant K23 AA017508 from the National Institute on Alcohol Abuse and Alcoholism at the National Institutes of Health. MM Miller has served on the speakers bureau for Alkermes plc and the physician advisory board for Braeburn Pharmaceuticals, Inc. D Rabago has nothing to disclose.

\section{References}

1. Groene O. Patient centredness and quality improvement efforts in hospitals: rationale, measurement, implementation. Int J Qual Health Care. 2011;23(5):531-537.

2. Institute of Medicine. Crossing the Quality Chasm: A New Health System for the 21st Century. Washington DC: National Academies Press; 2001.

3. Bertakis KD, Azari R. Patient-centered care is associated with decreased health care utilization. J Am Board Fam Med. 2011;24(3):229-239.

4. Chue P. The relationship between patient satisfaction and treatment outcomes in schizophrenia. J Psychopharmacol. 2006;20(Suppl 6): $38-56$

5. Glickman SW, Boulding W, Manary M, et al. Patient satisfaction and its relationship with clinical quality and inpatient mortality in acute myocardial infarction. Circ Cardiovasc Qual Outcomes. 2010;3(2): 188-195.

6. Fenton JJ, Jerant AF, Bertakis KD, Franks P. The cost of satisfaction: a national study of patient satisfaction, health care utilization, expenditures, and mortality. Arch Intern Med. 2012;172(5):405-411.

7. Fisher ES, Wennberg DE, Stukel TA, Gottlieb DJ, Lucas FL, Pinder EL. The implications of regional variations in Medicare spending. Part 2: health outcomes and satisfaction with care. Ann Intern Med. 2003;138(4):288-298

8. Chang JT, Hays RD, Shekelle PG, et al. Patients' global ratings of their health care are not associated with the technical quality of their care. Ann Intern Med. 2006;144(9):665-672.
9. Schneider EC, Zaslavsky AM, Landon BE, Lied TR, Sheingold S, Cleary PD. National quality monitoring of Medicare health plans: the relationship between enrollees' reports and the quality of clinical care. Med Care. 2001;39(12):1313-1325.

10. Lee DS, Tu JV, Chong A, Alter DA. Patient satisfaction and its relationship with quality and outcomes of care after acute myocardial infarction. Circulation. 2008;118(19):1938-1945.

11. Rahmqvist M, Bara AC. Patient characteristics and quality dimensions related to patient satisfaction. Int J Qual Health Care. 2010;22(2): 86-92.

12. Mold JW, Lawler F, Schauf KJ, Aspy CB. Does patient assessment of the quality of the primary care they receive predict subsequent outcomes?: An Oklahoma Physicians Resource/Research Network (OKPRN) study. J Am Board Fam Med. 2012;25(4):e1-e12.

13. Zgierska A, Miller M, Rabago D. Patient satisfaction, prescription drug abuse, and potential unintended consequences. JAMA. 2012;307(13): 1377-1378.

14. Lembke A. Why doctors prescribe opioids to known opioid abusers. N Engl J Med. 2012;367(17):1580-1581.

15. Falkenberg K. Why rating your doctor is bad for your health. Forbes. January 21, 2013. Available from: http://www.forbes.com/sites/ kaifalkenberg/2013/01/02/why-rating-your-doctor-is-bad-for-yourhealth/. Accessed June 6, 2013.

16. O'Reilly KB. Patient satisfaction: when a doctor's judgment risks a poor rating. American Medical News. November 26, 2012. Available from: http:/www.ama-assn.org/amednews/2012/11/26/prsa1126.htm. Accessed June 6, 2013.

17. Sullivan W. Dying for satisfaction. Emergency Physicians Monthly. March 20, 2012. Available from: http://www.epmonthly.com/columns/ in-my-opinion/dying-for-satisfaction/. Accessed February 6, 2013.

18. Robbins RA, Raschke RA. A new paradigm to improve patient outcomes: a tongue-in-cheek look at the cost of patient satisfaction. Southwest J Pulm Crit Care. 2012;5:33-35.

19. Press Ganey mantra: suck it up. Emergency Physicians Monthly. January 2, 2013. Available from: http://www.epmonthly.com/whitecoat/2013/01/ press-ganey-mantra-suck-it-up/. Accessed February 6, 2012.

20. Elijovich F. Of sommeliers and wine drinkers. Arch Intern Med. 2012;172(14):1111-1112

21. Friedberg MW, Gelb Safran D, Schneider EC. Satisfied to death: a spurious result? Arch Intern Med. 2012;172(14):1112-1113.

22. Sirovich BE. How to feed and grow your health care system: comment on "The cost of satisfaction". Arch Intern Med. 2012;172(5): 411-413.

23. Maciejewski ML, Harman JS. Patient satisfaction associated with lower emergency department use but more hospitalisations and higher costs and mortality. Evid Based Med. 2013;18(1):e10.

24. Manary MP, Boulding W, Staelin R, Glickman SW. The patient experience and health outcomes. N Engl J Med. 2013;368(3):201-203.

25. Patient expectations regarding opioid prescriptions creating costly conflicts for physicians. The BackLetter. 2012;27(6):67.

26. Crabtree BF, Miller WL. Using Codes and Code Manuals: A Template Organizing Style of Interpretation. In: Crabtree BF, Miller WL, editors. Doing Qualitative Research, 2nd edition. Thousand Oaks, CA: Sage; 1999:163-177.

27. Brett AS, McCullough LB. Addressing requests by patients for nonbeneficial interventions. JAMA. 2012;307(2):149-150.

28. American Medical Association (AMA). Strategic focus [web page on the Internet]. Chicago, IL: AMA; nd. http://www.ama-assn.org/ama/ pub/about-ama/strategic-focus.page. Accessed February 25, 2013.

29. Center for Workforce Studies, Association of American Medical Colleges (AAMC). Recent Studies and Reports on Physician Shortages in the US. Washington DC: AAMC; 2012. Available from: https://www. aamc.org/download/100598/data. Accessed May 31, 2013.

30. National Center for Health Statistics. Health, United States, 2011: With Special Feature on Socioeconomic Status and Health. Report No 2012-1232. Hyattsville, MD: US Government Printing Office; 2012. Available from: http://www.cdc.gov/nchs/data/hus/hus11.pdf. Accessed February 2, 2014. 
31. Boucher HW, Talbot GH, Bradley JS, et al. Bad bugs, no drugs: no ESKAPE! An update from the Infectious Diseases Society of America. Clin Infect Dis. 2009;48(1):1-12.

32. Executive Office of the President of the United States. Epidemic: Responding to America's Prescription Drug Abuse Crisis. Washington DC: Executive Office of the President of the United States; 2011. Available from: http:/www.whitehouse.gov/sites/default/files/ondcp/ issues-content/prescription-drugs/rx_abuse_plan_0.pdf. Accessed February 6, 2012.

33. Meyer Z. Medicare payments tied to patient surveys. U S A Today. December 24, 2012. Available from: http://www.usatoday.com/ story/money/business/2012/12/24/hospitals-satisfaction-surveysmedicare/1788833/. Accessed March 1, 2013.

34. Adamy J. US ties hospital payments to making patients happy. Wall Street Journal. October 14, 2012. Available from: http://online.wsj. com/article/SB10000872396390443890304578010264156073132. html. Accessed March 1, 2013.
35. Shill J, Taylor DM, Ngui B, et al. Factors associated with high levels of patient satisfaction with pain management. Acad Emerg Med. 2012;19(10):1212-1215.

36. American Medical Association House of Delegates (A-13). Resolution 18: pain management and the hospital value-based purchasing program. In: Report of Reference Committee G. AMA House of Delegates 2013 Annual Meeting, Chicago, IL, Jun 13-19, 2013. Available from: http://www.ama-assn.org/assets/meeting/2013a/a13-refcomm-g.pdf. Accessed June 30, 2013.

37. Loewenstein G, Volpp KG, Asch DA. Incentives in health: different prescriptions for physicians and patients. JAMA. 2012;307(13):1375-1376.

38. Mannion R, Braithwaite J. Unintended consequences of performance measurement in healthcare: 20 salutary lessons from the English National Health Service. Intern Med J. 2012;42(5):569-574.

39. Rittenhouse DR, Mertz E, Keane D, Grumbach K. No exit: an evaluation of measures of physician attrition. Health Serv Res. 2004;39(5): 1571-1588.

\section{Publish your work in this journal}

Patient Preference and Adherence is an international, peer-reviewed, open access journal focusing on the growing importance of patient preference and adherence throughout the therapeutic continuum. Patient satisfaction, acceptability, quality of life, compliance, persistence and their role in developing new therapeutic modalities and compounds to optimize clinical outcomes for existing disease states are major areas of interest. This journal has been accepted for indexing on PubMed Central. The manuscript management system is completely online and includes a very quick and fair peer-review system. Visit http://www.dovepress.com/ testimonials.php to read real quotes from published authors. 